\title{
Analiza składowych emisji GHG z upraw rzepaku wykorzystywanego do produkcji estrów metylowych kwasów tłuszczowych
}

\begin{abstract}
W ostatnich latach bardzo ważną rolę w branży paliwowej odgrywają biopaliwa. Stawiane są im jednak odrębne wymagania. Poza kwestiami jakościowymi niezbędne jest wykazanie, że dane biopaliwo jest w stanie ograniczyć emisję gazów cieplarnianych na minimalnym zadanym poziomie. Sama produkcja biokomponentu także generuje pewną ilość emisji GHG. Oblicza się ją już od momentu pozyskiwania surowców. W niniejszej pracy przeanalizowano etap uprawy rzepaku i zbadano, jak na generowaną tam emisję GHG oddziałują poszczególne czynności i procesy agrotechniczne. Na podstawie przeprowadzonych obliczeń określono, że największy wpływ na generowaną podczas upraw emisję mają nawozy azotowe oraz występująca emisja podtlenku azotu zwana ,emisją polową”.
\end{abstract}

Słowa kluczowe: rzepak, emisja GHG, uprawa, estry metylowe kwasów tłuszczowych, cykl życia.

\section{Analysis of the components of the GHG emissions from the cultivation of rapeseed for the production of fatty acids methyl esters (FAME)}

\begin{abstract}
In recent years, biofuels have been playing a very important role in the fuel industry. Apart from their quality, it is necessary to prove that the biofuel is able to reduce greenhouse gas emissions at the minimal preset level. Production of the biofuels also generate GHG emissions. It is calculated from the moment of cultivation of the raw materials. In this paper, the stage of rapeseed cultivation was analyzed. The impact of various activities and agronomic operations on the total emissions from the cultivation was studied. On the basis of the calculations, it was determined that the greatest impact on the emissions from the cultivation stage, are as a result of nitrogenous fertilizers and nitrous oxide emissions called "field emission".
\end{abstract}

Key words: rapeseed, GHG emissions, cultivation, fatty acids methyl esters, life cycle.

\section{Wstęp}

Ważną cechą charakteryzującą każde biopaliwo jest poziom ograniczenia emisji gazów cieplarnianych, wynikający z zastąpienia tym biopaliwem jego odpowiednika kopalnego. Należy jednak pamiętać, że także biopaliwa niosą ze sobą pewną emisję gazów cieplarnianych, która powstaje podczas ich produkcji. W przypadku biopaliw uzyskiwanych $\mathrm{z}$ surowców rolnych jedną $\mathrm{z}$ istotnych składowych jest emisja z etapu uprawy. Aby przekonać się, jak duży ma ona wpływ na łączną emisję generowaną w cyklu życia biopaliwa, poddano analizie proces uprawy rzepaku w warunkach polskich pod kątem oceny jego emisyjności.

Wytyczne w zakresie obliczania emisji gazów cieplarnia- nych w cyklu życia biopaliwa, w tym także dla etapu uprawy, zostały zdefiniowane w artykule 19 dyrektywy RED [8]. Załącznik V, część C, tego dokumentu precyzuje metodykę obliczania emisji GHG, której podstawą jest wzór:

$$
E=e_{e c}+e_{l}+e_{p}+e_{t d}+e_{u}-e_{s c a}-e_{c c s}-e_{c c r}-e_{e e}
$$

gdzie:

$E$ - emisja całkowita spowodowana stosowaniem paliwa,

$e_{e c}-$ emisja związana z wydobyciem lub uprawą surowców,

$e_{l}$ - emisja w ujęciu rocznym powodowana zmianami ilości pierwiastka węgla w związku ze zmianą sposobu użytkowania gruntu, 
$e_{p}$ - emisja wywołana procesami technologicznymi,

$e_{t d}-$ emisja związana $\mathrm{z}$ transportem i dystrybucją,

$e_{u}$ - emisja spowodowana stosowanym paliwem,

$e_{s c a}-$ wartość ograniczenia emisji wywołanej akumulacją pierwiastka węgla w glebie dzięki lepszej gospodarce rolnej,

$e_{c c s}$ - ograniczenie emisji spowodowanej wychwytywaniem ditlenku węgla i składowaniem w głębokich strukturach geologicznych,

$e_{c c r}$ - ograniczanie emisji związane z wychwytywaniem i zastępowaniem ditlenku węgla,

$e_{e e}$ - ograniczenie emisji dzięki zwiększonej produkcji energii elektrycznej w wyniku kogeneracji.

Zgodnie z pkt. c artykułu 19 dyrektywy RED w obliczeniach możliwe jest stosowanie kombinacji wartości rzeczywistych i cząstkowych wartości standardowych. Etap uprawy surowców jest etapem charakterystycznym, ponieważ poza wartościami rzeczywistymi, standardowymi, możliwe jest tu wykorzystywanie również średnich emisji GHG. Ustęp drugi artykułu 19 [8] nakłada na państwa członkowskie obowiązek złożenia sprawozdania zawierającego wykaz obszarów na ich terytorium zaklasyfikowanych na poziomie $2 \mathrm{w}$ nomenklaturze jednostek terytorialnych do celów statystycznych (NUTS) lub na bardziej szczegółowym poziomie NUTS, zgodnie z Rozporzadzeniem (WE) nr 1059/2003 Parlamentu Europejskiego i Rady z dnia 26 maja 2003 r. w sprawie ustalenia wspólnej klasyfikacji jednostek terytorialnych do celów statystycznych (NUTS). Na tych obszarach typowy poziom emisji gazów cieplarnianych wynikających z upraw surowców rolnych może być niższy od poziomu emisji określonego w Szczególowych wartościach standardowych z upraw (załącznik V, część D do dyrektywy [8]) lub równy temu poziomowi, łącznie z opisem metody i danych wykorzystanych do sporządzenia wykazu.

\section{Część doświadczalna}

\section{Dane wejściowe do obliczeń}

Kwestie sposobu alokacji oraz innych czynników wpływających na wynik emisji GHG na etapie produkcji biokomponentu były już przedmiotem wcześniejszych analiz [1-3]. W ramach tej pracy postawiono za cel ustalenie wszystkich składowych emisji GHG powstającej podczas uprawy surowca używanego do wyprodukowania finalnego biokomponentu oraz określenie ich istotności. W niniejszym artykule poddano analizie rzepak - surowiec rolny najczęściej wykorzystywany w Polsce do produkcji oleju roślinnego, z któ-

Tablica 1. Dane rolnicze, na podstawie których wyznaczono składowe emisji GHG

\begin{tabular}{|c|c|c|c|c|c|c|c|c|c|}
\hline \multirow{3}{*}{$\begin{array}{l}\text { Lp. } \\
\text { gospodarstwa }\end{array}$} & \multirow{3}{*}{$\begin{array}{l}\text { Plon } \\
{[\mathrm{t} / \mathrm{ha}]}\end{array}$} & \multirow{3}{*}{$\begin{array}{c}\text { Wilgotność } \\
\text { ziarna } \\
{[\%]}\end{array}$} & \multicolumn{7}{|c|}{ Zużycie materiałów } \\
\hline & & & \multicolumn{4}{|c|}{ nawozy sztuczne [kg/ha] } & \multirow{2}{*}{$\begin{array}{c}\text { Paliwo } \\
(\mathrm{ON}) \\
{[1 / \mathrm{ha}]}\end{array}$} & \multirow{2}{*}{$\begin{array}{c}\text { Pestycydy } \\
{[\mathrm{kg} / \mathrm{ha}]}\end{array}$} & \multirow{2}{*}{$\begin{array}{c}\text { Materiał } \\
\text { siewny } \\
{[\mathrm{kg} / \mathrm{ha}]}\end{array}$} \\
\hline & & & $\mathrm{N}$ & $\mathrm{P}_{2} \mathrm{O}_{5}$ & $\mathrm{~K}_{2} \mathrm{O}$ & $\mathrm{CaO}$ & & & \\
\hline 1 & 4,16 & 7,45 & 182,05 & 40,33 & 72,54 & 55,20 & 80,79 & 2,00 & 2,97 \\
\hline 2 & 4,21 & 7,89 & 182,00 & 46,00 & 75,00 & 66,50 & 82,94 & 1,97 & 3,26 \\
\hline 3 & 3,60 & 7,70 & 167,60 & 68,78 & 105,52 & 24,50 & 103,17 & 1,93 & 2,92 \\
\hline 4 & 4,10 & 7,96 & 208,29 & 61,95 & 87,85 & 30,00 & 88,06 & 2,05 & 3,02 \\
\hline 5 & 3,87 & 8,79 & 159,45 & 55,11 & 84,72 & 32,20 & 72,92 & 1,80 & 4,10 \\
\hline 6 & 4,08 & 7,70 & 146,55 & 63,71 & 95,38 & 19,00 & 79,13 & 1,60 & 2,93 \\
\hline 7 & 3,83 & 7,41 & 183,35 & 75,89 & 63,62 & 95,00 & 107,97 & 2,30 & 3,91 \\
\hline 8 & 3,86 & 8,12 & 168,58 & 67,29 & 96,96 & 20,50 & 87,14 & 1,98 & 2,69 \\
\hline 9 & 3,90 & 8,06 & 196,05 & 25,90 & 112,90 & 67,30 & 103,25 & 1,66 & 2,74 \\
\hline 10 & 4,09 & 8,00 & 124,59 & 51,86 & 165,07 & 60,00 & 81,86 & 2,11 & 2,67 \\
\hline 11 & 3,99 & 7,42 & 151,22 & 58,89 & 88,33 & 10,00 & 86,39 & 2,00 & 2,50 \\
\hline 12 & 4,38 & 7,56 & 175,87 & 77,27 & 120,21 & 21,00 & 77,00 & 2,01 & 2,66 \\
\hline 13 & 4,60 & 8,19 & 182,63 & 54,26 & 82,68 & 47,40 & 83,95 & 1,98 & 3,08 \\
\hline 14 & 4,00 & 8,43 & 179,25 & 48,51 & 95,69 & 30,00 & 56,55 & 2,03 & 2,79 \\
\hline 15 & 4,23 & 7,83 & 179,63 & 46,05 & 115,71 & 22,60 & 86,83 & 1,97 & 3,03 \\
\hline Średnia & 4,06 & 7,90 & 172,47 & 56,12 & 97,48 & 40,08 & 85,20 & 1,96 & 3,02 \\
\hline
\end{tabular}


rego na dalszym etapie wytwarzane są estry metylowe kwasów tłuszczowych (FAME). Obliczenia wykonane w ramach niniejszej pracy oparto na danych rzeczywistych pozyskanych od polskich gospodarstw rolnych, które miały charakter wielkotowarowy oraz pochodziły z różnych obszarów kraju.

Gospodarstwa rolne udzieliły informacji na temat powierzchni uprawy, wilgotności nasion rzepaku, nazwy i ilości stosowanych nawozów sztucznych, nazwy i ilości używanych środków ochrony roślin, ilości materiału siewnego, zużycia paliw do napędzania maszyn rolniczych oraz pozostałych źródeł energii użytej podczas uprawy. Otrzymane dane zostały uśrednione i posłużyły jako dane wejściowe do obliczeń emisji gazów cieplarnianych. W tablicy 1 znajdują się dane uzyskane z poszczególnych gospodarstw oraz wyliczone na tej podstawie wartości średnie.

\section{Przeprowadzenie obliczeń}

Wykorzystując dane z gospodarstw rolnych, wyznaczono wartości średnie i na ich podstawie oszacowano średnie emisje GHG w rozbiciu na poszczególne składowe. Aby je wyznaczyć, konieczne było pozyskanie niezbędnych wskaźników emisji GHG. Wszystkie użyte wskaźniki wraz ze źródłem ich pochodzenia zestawiono w tablicy 2 .

Tablica 2. Wskaźniki emisji GHG wykorzystane w obliczeniach

\begin{tabular}{|c|c|c|}
\hline $\begin{array}{l}\text { Rodzaj wskaźnika } \\
\text { emisji GHG }\end{array}$ & $\begin{array}{c}\text { Wartość wskaźnika } \\
\text { emisji GHG }\end{array}$ & Źródło \\
\hline \multicolumn{3}{|c|}{ 1. Nawozy sztuczne (poszczególne składniki) } \\
\hline $\mathrm{N}$ & $3,253 \mathrm{~kg} \mathrm{CO} 2 \mathrm{eq} / \mathrm{kg}$ & Wskaźnik dla Polski [4] \\
\hline $\mathrm{P}_{2} \mathrm{O}_{5}$ & $1,011 \mathrm{~kg} \mathrm{CO} 2 \mathrm{eq} / \mathrm{kg}$ & \multirow{6}{*}{ Biograce 4d [5] } \\
\hline $\mathrm{K}_{2} \mathrm{O}$ & $0,576 \mathrm{~kg} \mathrm{CO} / \mathrm{kg}$ & \\
\hline $\mathrm{CaO}$ & $0,129 \mathrm{~kg} \mathrm{CO}{ }_{2} \mathrm{eq} / \mathrm{kg}$ & \\
\hline 2. Środki ochrony roślin & $10,971 \mathrm{~kg} \mathrm{CO} \mathrm{CO}_{2} \mathrm{eqg}$ & \\
\hline 3. Nasiona rzepaku & $0,730 \mathrm{~kg} \mathrm{CO}{ }_{2} \mathrm{eq} / \mathrm{kg}$ & \\
\hline 4. Olej napędowy & $3,142 \mathrm{~kg} \mathrm{CO}{ }_{2} \mathrm{eq} / 1$ & \\
\hline 5. Emisja polowa $\mathrm{N}_{2} \mathrm{O}$ & $\begin{array}{l}4,870 \mathrm{~kg} \mathrm{CO} \mathrm{Cq}_{2} / \mathrm{kg} \\
\text { nawozu azotowego }\end{array}$ & Wskaźnik ISCC [7] \\
\hline
\end{tabular}

Na podstawie danych zawartych w tablicach 1 i 2 wyznaczono poszczególne składowe wyrażone w $\mathrm{kg} \mathrm{CO}_{2}$ eq/ha oraz sumaryczną emisję GHG z uprawy wyrażoną w $\mathrm{kg} \mathrm{CO}$ eq/ha oraz $\mathrm{kg} \mathrm{CO}$ eq/t rzepaku (po uwzględnieniu średniego plonu z hektara). Procentowe udziały poszczególnych składowych zobrazowano na rysunku 1 .

Ze względu na to, że na potrzeby spełnienia wymagań dyrektywy 2009/28/WE [8] emisja GHG dla etapu upraw podawana jest $\mathrm{w}$ g $\mathrm{CO}_{2}$ eq $\mathrm{w}$ przeliczeniu na $1 \mathrm{MJ}$ uzyskanego biopaliwa, otrzymaną emisję dla tony surowca rolne-

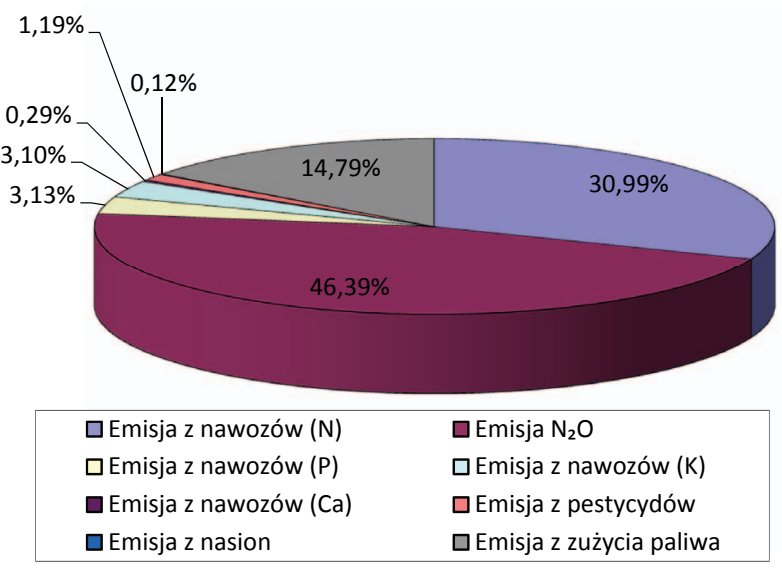

Rys. 1. Procentowy udział poszczególnych składowych emisji GHG z etapu uprawy rzepaku

go należy przeliczyć z uwzględnieniem wszystkich następujących po sobie procesów przeróbki. W przypadku rzepaku są to najczęściej procesy prowadzące do wytworzenia estrów metylowych kwasów tłuszczowych (FAME). W tym celu prowadzi się obliczenia z wykorzystaniem współczynników konwersji dla danego procesu przeróbki oraz stosuje się współczynniki alokacji emisji uwzględniające rodzaj otrzymywanych produktów: głównego oraz ubocznych. W efekcie wpływ na ostateczny wynik może mieć dobór zastosowanych w obliczeniach współczynników konwersji z procesów tłoczenia oleju oraz produkcji FAME, a także współczynników alokacji zależnych od udziału masowego poszczególnych produktów procesu i ich wartości opałowej. W związku z tym ta sama wartość emisji wyliczona dla etapu uprawy, wyrażona $\mathrm{w} \mathrm{kg} \mathrm{CO}_{2} \mathrm{eq}$ na tonę rzepaku, może w zależności od przyjętych do symulacji wskaźników konwersji i alokacji na dalszych etapach dać odmienne wyniki w jednostkach $\mathrm{CO}_{2}$ eq/MJ FAME. Wielkość współczynnika konwersji zależy od wydajności procesu tłoczenia oleju (zależnej m.in. od zawartości oleju w nasionach) oraz efektywności procesu transestryfikacji. Natomiast współczynniki alokacji emisji GHG, czyli rozdziału ilości emisji pomiędzy produkty główne i uboczne (za wyjątkiem odpadów procesowych), zależą od ich zawartości energetycznej w strumieniu wyjściowym. W obliczeniach najczęściej korzysta się z danych podanych przez Biograce [4]. Wartości te zamieszczono w tablicy 4.

Na podstawie powyższych współczynników można dokonać przeliczenia wskaźnika wyrażonego w $\mathrm{kg} \mathrm{CO}_{2}$ eq/t rzepaku z tablicy 3 na jednostki g $\mathrm{CO}_{2}$ eq/MJ FAME. Na tej podstawie oszacowany wskaźnik emisji GHG w g $\mathrm{CO}_{2}$ eq w przeliczeniu na 1 MJ FAME wyniósł 18,62 . W tablicy 5 porównano 
średnią wartość otrzymaną dla wybranych polskich gospodarstw $\mathrm{z}$ wyliczonymi średnimi w innych krajach (regionach) oraz zakres średnich danych z Polski z lat 2005-2010. Dane zamieszczone w tablicy 5 dla przedstawionych krajów zaczerpnięto z wytycznych Komisji Europejskiej [5].
Tablica 4. Współczynniki konwersji zastosowane w kalkulatorze Biograce

\begin{tabular}{|l|l|c|}
\hline \multicolumn{1}{|c|}{ Proces } & \multicolumn{1}{|c|}{ Rodzaj współczynnika } & \multicolumn{1}{c|}{ Wartość } \\
\hline Tłoczenie oleju rzepakowego & Uzysk oleju (nierafinowanego) & $0,613 \mathrm{MJ}_{\text {olju }} / \mathrm{MJ}_{\text {rzepaku }}$ \\
\hline Rafinacja oleju rzepakowego & Uzysk oleju (rafinowanego) & $0,960 \mathrm{MJ}_{\text {oleju }} / \mathrm{MJ}_{\text {oleju }}$ \\
\hline Produkcja FAME & Uzysk FAME & $0,994 \mathrm{MJ}_{\mathrm{FAME}} / \mathrm{MJ}_{\text {oleju }}$ \\
\hline \multicolumn{3}{|c|}{ Wartość opałowa } \\
\hline Rzepak & \multicolumn{2}{|c|}{$26,4 \mathrm{MJ} / \mathrm{kg}$} \\
\hline Olej rzepakowy & $37,0 \mathrm{MJ} / \mathrm{kg}$ \\
\hline FAME & \multicolumn{2}{|c|}{$37,2 \mathrm{MJ} / \mathrm{kg}$} \\
\hline
\end{tabular}

Tablica 5. Porównanie otrzymanego wyniku na tle wartości deklarowanych w innych krajach

\begin{tabular}{|l|c|}
\hline \multicolumn{1}{|c|}{ Kraj (region) } & Emisja GHG w g CO ${ }_{2}$ eq/MJ FAME \\
\hline Belgia (Flanders) & 20,20 \\
\hline Holandia (Flevoland) & 23,20 \\
\hline Litwa (Kaunas County) & 24,56 \\
\hline Portugalia (Centro) & 33,00 \\
\hline Austria (Burgenland) & 19,36 \\
\hline Bułgaria (Severozapaden) & 14,79 \\
\hline Czechy (Praha) & 23,10 \\
\hline Niemcy (Hannover) & 23,80 \\
\hline Rumunia (Brasov) & 24,00 \\
\hline Polska (min.-maks.) lata 2005-2010 & 18,62 \\
\hline $\begin{array}{l}\text { Średni wynik dla wybranych polskich gospodarstw wyliczony na } \\
\text { podstawie danych z lat 2010-2015, w ramach niniejszej pracy }\end{array}$ & 21,32 (podkarpackie) - 28,25 (podlaskie) \\
\hline
\end{tabular}

\section{Podsumowanie}

Wyznaczone poszczególne składowe emisji GHG z uprawy rzepaku wskazują, że największa emisja gazów cieplarnianych na etapie uprawy związana jest $\mathrm{z}$ emisją polową podtlenków azotu oraz z zużyciem nawozów azotowych. Trzecia co do istotności jest składowa emisji wynikająca z zużycia paliw do napędzania maszyn rolniczych. Wyznaczona w ramach pracy emisja $\mathrm{N}_{2} \mathrm{O}$ nie jest wartością rzeczywistą - została określona na podstawie algorytmu, który wiąże wielkość tej emisji z zużyciem nawozów azotowych. Reszta składowych, czyli emisje z pozostałych nawozów mineralnych, pestycydów oraz użytych nasion, stanowi niewiele ponad 7\% całkowitej emisji. Największą możliwość do obniżenia emisji GHG z uprawy rzepaku dawać może zatem ograniczenie zużycia nawozów azotowych. Należy mieć jednak na uwadze fakt, że stosowanie niższych dawek może przyczynić się do zmniejszenia plonu z hektara. W tym przypadku obliczana emisja GHG w przeliczeniu na 1 hektar uprawy niewątpliwie ulegnie obniżeniu, jednak emisja GHG w przeliczeniu na 1 tonę uzyskanego rzepaku może wzrosnąć.
Obniżenie zużycia paliw może być trudne do zrealizowania, biorąc pod uwagę, że w dużych gospodarstwach towarowych w ostatnich latach nastąpiła już poprawa agrotechniki i deklarowane ilości paliw zużywane są w wyniku pracy na nowoczesnym sprzęcie. Znajduje to również odzwierciedlenie w określonym w ramach niniejszej pracy wskaźniku emisji GHG, który jest niższy od wskaźników wyliczanych dla Polski w latach 2005-2010. Obliczona wartość jest również konkurencyjna względem wartości określonych kilka lat temu w innych krajach europejskich. Biorąc pod uwagę powyższe fakty, można stwierdzić, że próba dalszego obniżania emisji GHG z upraw rzepaku w Polsce poprzez optymalizację produkcji będzie trudna do zrealizowania. Ze względu na dotychczasowy sposób kalkulacji emisji polowej, realne szanse na poprawę wyników dawać może przeprowadzenie badań rzeczywistej emisji podtlenku azotu podczas upraw na terenie Polski. Należy mieć jednak na uwadze to, że taki projekt wiązałby się ze sporymi nakładami finansowymi, a czas jego realizacji musiałby być odpowiednio długi. 
Artykuł nadesłano do Redakcji 19.01.2017 r. Zatwierdzono do druku 28.03.2017 r.

Artykuł powstał na podstawie pracy statutowej pt.: Analiza składowych emisji GHG z upraw surowców do produkcji FAME-praca INiG - PIB na zlecenie MNiSW; nr zlecenia: DK-4100-54/16.

\section{Literatura}

[1] Berdechowski K.: Wytyczne obliczania emisji GHG w cyklu życia paliwa alternatywnego wytwarzanego z odpadów komunalnych. Nafta-Gaz 2015, nr 4, s. 236-241.

[2] Berdechowski K., Duda A., Łaczek T.: Emisja w procesie hydrokonwersji bioolejów jako składnik emisji gazów cieplarnianych w cyklu życia (LCA) olejów napędowych. Nafta-Gaz 2012, nr 4, s. 254-259.

[3] Berdechowski K., Rogowska D.: Ocena wpływu sposobu alokacji emisji w procesie produkcji biopaliwa na wartość emisji gazów cieplarnianych. Nafta-Gaz 2013, nr 3, s. 226-234.

[4] Biograce; http://www.biograce.net/content/ghgcalculationtools/recognisedtool/ (dostęp: wrzesień 2016).

[5] European Commission; http://ec.europa.eu/energy/en/topics/ renewable-energy/biofuels (dostęp: maj 2016).

[6] Faber A., Jarosz Z., Borek R., Borzęcka-Walker M., Syp A., Pudełko R.: Poziom emisji gazów cieplarnianych $\left(\mathrm{CO}_{2}, \mathrm{~N}_{2} \mathrm{O}\right.$, $\left.\mathrm{CH}_{4}\right)$ dla upraw pszenicy, pszenżyta, kukurydzy $i$ żyta przeznaczonych do produkcji bioetanolu oraz upraw rzepaku przeznaczonych do produkcji biodiesla. Ekspertyza wykonana na zlecenie Ministerstwa Rolnictwa i Rozwoju Wsi, Instytut Uprawy Nawożenia i Gleboznawstwa - Państwowy Instytut Badawczy, Puławy, wrzesień 2011.
[7] ISCC System: International Sustainability \& Carbon Certification; http://www.iscc-system.org/en/certification-process/ isccsystemdocuments/iscc-eu/ (dostęp: lipiec 2016).

\section{Akty prawne i normatywne}

[8] Dyrektywa Parlamentu Europejskiego i Rady 2009/28/WE $z$ dnia 23 kwietnia 2009 r. w sprawie promowania stosowania energii ze źródet odnawialnych zmieniająca $i$ w nastepstwie uchylajaca dyrektywy 2001/77/WE oraz 2003/30/WE (tekst mający znaczenie dla EOG) (Dz. Urz. UE L 140 z 05.06.2009, z późn. zm.).

\section{OFERTA}

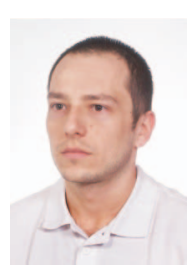

Mgr Kamil BERDECHOWSKI

Starszy specjalista badawczo-techniczny w Zakładzie Paliw i Procesów Katalitycznych. Instytut Nafty i Gazu - Państwowy Instytut Badawczy ul. Lubicz 25 A

31-503 Kraków

E-mail: kamil.berdechowski@inig.pl

\section{ZAKŁAD PALIW I PROCESÓW KATALITYCZNYCH}

Zakres działania:

- opracowywanie, rozwijanie i wdrażanie technologii produkcji LPG, benzyn silnikowych, paliw lotniczych, olejów napędowych, biopaliw I i II generacji oraz olejów opałowych, prowadzenie nadzoru technologicznego nad opracowanymi i wdrożonymi technologiami;

- ocena i atestacja komponentów paliwowych, w tym biokomponentów I i II generacji oraz komponentów ze źródeł alternatywnych;

- opracowywanie technologii uszlachetniania paliw i biopaliw silnikowych oraz olejów opałowych i rozpuszczalników, dobór odpowiednich dodatków uszlachetniających;

- $\quad$ wykonywanie badań i ekspertyz dotyczących jakości paliw i biopaliw silnikowych, olejów opałowych, rozpuszczalników i ich komponentów oraz ocena zgodności ze specyfikacją;

- ocena skażenia mikrobiologicznego paliw w systemie produkcji i dystrybucji;

- ocena właściwości niskotemperaturowych olejów napędowych i opałowych;

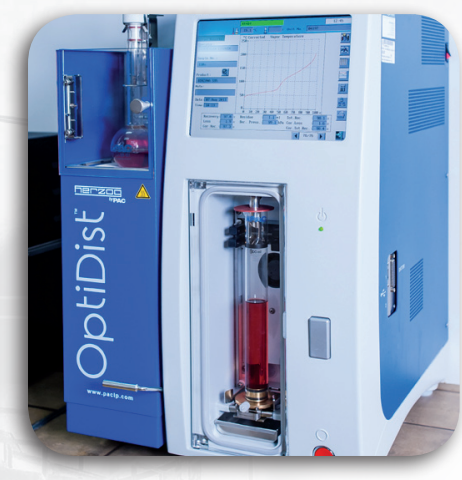

- badania stabilności pozostałościowych olejów opałowych i kompatybilności ich komponentów;

- opracowywanie, rozwijanie i wdrażanie nowych wodorowych procesów katalitycznych, ocena testowa i procesowa katalizatorów stosowanych w przemyśle rafineryjnym w procesach zeoformingu, hydroodsiarczania, hydrorafinacji i katalitycznego odparafinowania;

- ocena oddziaływania na środowisko paliw, biopaliw i innych produktów pochodzących z przemysłu rafineryjnego i petrochemicznego w oparciu o analizę cyklu życia produktu (LCA).

Kierownik: dr inż. Jan Lubowicz

Adres: ul. Łukasiewicza 1, 31-429 Kraków

Telefon: 126177550

Faks: 126177522

E-mail: jan.lubowicz@inig.p 